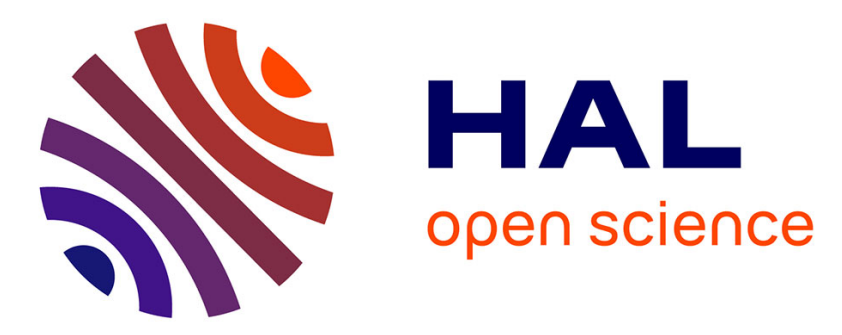

\title{
Distinguishing feral and managed honeybees (Apis mellifera) using stable carbon isotopes
}

Lucy Anderson, Travis Dynes, Jennifer Berry, Keith Delaplane, Lydia

Mccormick, Berry Brosi

\section{- To cite this version:}

Lucy Anderson, Travis Dynes, Jennifer Berry, Keith Delaplane, Lydia Mccormick, et al.. Distinguishing feral and managed honeybees (Apis mellifera) using stable carbon isotopes. Apidologie, 2014, 45 (6), pp.653-663. 10.1007/s13592-014-0283-4 . hal-01234765

\section{HAL Id: hal-01234765 \\ https://hal.science/hal-01234765}

Submitted on 27 Nov 2015

HAL is a multi-disciplinary open access archive for the deposit and dissemination of scientific research documents, whether they are published or not. The documents may come from teaching and research institutions in France or abroad, or from public or private research centers.
L'archive ouverte pluridisciplinaire HAL, est destinée au dépôt et à la diffusion de documents scientifiques de niveau recherche, publiés ou non, émanant des établissements d'enseignement et de recherche français ou étrangers, des laboratoires publics ou privés. 


\title{
Distinguishing feral and managed honeybees (Apis mellifera) using stable carbon isotopes
}

\author{
Lucy M. Anderson ${ }^{1}$, Travis M. Dynes ${ }^{1}$, Jennifer A. Berry ${ }^{2}$, Keith S. Delaplane $^{2}$, \\ Lydia L. McCormick ${ }^{1}$, Berry J. Brosi ${ }^{1}$ \\ ${ }^{1}$ Department of Environmental Studies, Emory University, 400 Dowman Drive, Suite E510, Atlanta, GA 30322, USA \\ ${ }^{2}$ Department of Entomology, University of Georgia, Athens, GA 30602, USA
}

Received 11 October 2013 - Revised 10 February 2014 - Accepted 24 February 2014

\begin{abstract}
The ability to distinguish feral and managed honeybees (Apis mellifera) has applications in studies of population genetics, parasite transmission, pollination, interspecific interactions, and bee breeding. We evaluated a diagnostic test based on theoretical differences in stable carbon isotope ratios generated by supplemental feeding. We evaluated (1) if carbon isotope ratios can distinguish feral and managed honeybees and (2) the temporal persistence of the signal after discontinuation of supplemental feeding. We compared carbon isotope ratios from four types of experimental colonies: feral, managed with and without supplemental feed, and managed with ${ }^{13} \mathrm{C}$-labeled glucose added to supplemental feed. There was a significant difference between the isotopic signatures of colonies receiving supplemental feed and unfed feral colonies. This difference, however, only persisted for a few weeks after supplemental feeding was discontinued, suggesting that this method may work best under a narrow range of conditions. This work highlights the potential for exploiting temporal turnover of carbon in bee tissues as a tool for studying nutrient flow in honeybee colonies.
\end{abstract}

feral honeybees / stable isotopes / carbon / photosynthesis pathways / isotopic fractionation

\section{INTRODUCTION}

Unlike most agricultural animal species, honeybees (Apis mellifera L.) exist in both managed and feral populations. This duality has potentially important implications for gene flow, transmission of parasites and pathogens, pollination of crops and native plants, and interactions with other pollinator species. Developing a consistent and inexpensive method for distinguishing feral and managed honeybees could lead to improvements in resistance breeding programs in managed bees as well as the ability to gather key data for agricultural and ecological studies.

Corresponding author: B. Brosi,

bbrosi@emory.edu

Manuscript editor: David Tarpy
Breeding programs, in which bees are bred for desirable characteristics such as disease resistance, have the potential to aid in the mitigation of ongoing honeybee declines. These declines, which include colony collapse disorder (e.g., Oldroyd 2007; Potts et al. 2010), pose a major threat to global agricultural production and food security worldwide and are likely driven by a range of threats. Pesticides, pathogens, and loss of traditional honeybee forage from urbanization are all probable drivers of bee decline, but Varroa destructor is thought to be the most significant factor (e.g., Rosenkranz et al. 2010; Martin et al. 2012). Feral bees, unmanaged by people, have potentially experienced intense natural selection for resistance to colony pests and parasites and may provide a source of resistance genes to honeybee breeders and scientists (e.g., Seeley 2007). Selective breeding efforts to improve 
honeybee resistance and/or tolerance to $V$. destructor and other disorders have been hindered by the inability to effectively distinguish unmanaged or "feral" honeybees from managed honeybees (Oxley et al. 2010; Spivak et al. 2011).

Differentiating between feral and managed honeybees also has implications for agricultural pollination and ecological studies. It would allow the potential to determine proportions of crops pollinated by managed versus feral bees and to investigate competition and resource partitioning between feral honeybees and native bees (e.g., whether honeybees sampled in the course of diversity or pollination studies are feral or managed). Moreover, little is known about the relative population sizes of feral honeybees and managed honeybees or their respective habitat suitability and preference.

Here, we evaluated a test based on stable isotopes of carbon to differentiate between feral and managed honeybees using isotope ratio mass spectrometry (IRMS) to determine the relative concentrations of stable carbon isotopes between tissues of feral and managed honeybees. Isotopes of an element have the same atomic number but a different number of neutrons which causes isotopes to vary in atomic mass. All atomic isotopes are either radioactive or stable, and each atomic element has both a dominant form (for example, carbon 12 or ${ }^{12} \mathrm{C}$ ) and rarer forms (e.g., ${ }^{13} \mathrm{C}$ which is stable or ${ }^{14} \mathrm{C}$ which is radioactive). Rarer isotopes react chemically in similar ways to the most abundant isotope of the specific element, but the mass differences between isotopes can lead to changes in reaction rates, which can then lead to differential concentrations of different isotopes - a process called "fractionation" (Peterson and Fry 1987; Brosi and Harkins 1937). Stable isotopes have been used widely in industrial applications (including quality control and tracing studies) and in ecological studies, including nutrient cycling, food webs, and animal movement and migration patterns (Hobson 1999; Kelly 2000; Kennedy et al. 1997; O'Brien et al. 2000; Ostrom et al. 1997; Phillips 2001).

In particular, stable isotopes of carbon are commonly used to distinguish between plants with different photosynthesis pathways. Photosynthesizing plants have developed three distinct metabolic pathways of carbon fixation: C3, $\mathrm{C} 4$, and CAM. The $\mathrm{C} 4$ carbon fixation process produces higher ratios of ${ }^{13} \mathrm{C}$ to ${ }^{12} \mathrm{C}$ in the plant relative to $\mathrm{C} 3$ fixation, yielding a distinct isotopic $\delta^{13} \mathrm{C}$ signature in IRMS (Farquhar et al. 1989). Many monocots, including the grass family (Poaceae) - of which corn, sugarcane, and wheat are members - undergo C4 carbon fixation (Koziet et al. 1993).

In the USA, honeybees typically forage on nectar-producing wildflowers which primarily utilize the C3 photosynthesis pathway. By contrast, the sugar solutions most frequently used by US beekeepers to supplement their colonies are made from corn syrup or sugarcane, both of which are $\mathrm{C} 4$ grass species and therefore have much greater concentrations of ${ }^{13} \mathrm{C}$. Notably, this property of detectable carbon isotope signatures based on photosynthetic pathways led to an early use of stable isotopes: the detection of adulteration of honey with supplemental sugars (cane sugar and/or corn syrup) (Doner \& White 1977; Elflein and Raezke 2008). Still, there is the caveat that sugar beets, a C3 species, are also used in sugar production, and some beekeepers may utilize beet sugar in feeding. Beyond signatures in honey, it has been shown that royal jelly, a secretion of protein, sugars, and amino acids fed to honeybee larvae, produced by honeybees with supplemental feed can be distinguished from royal jelly produced by honeybees not receiving this feed (Daniele et al. 2011).

Because carbon isotopes can be used to detect adulteration of honey and royal jelly with supplemental sugars, we hypothesized that carbon isotopes would also allow for distinguishing feral from managed honeybees given that most managed bees are given supplemental sugars from $\mathrm{C} 4$ photosynthesis pathway plants (corn and sugar cane). Specifically, in this study, we had two distinct objectives. Our first objective was to determine if honeybee tissues from feral versus managed bees show a difference in isotopic signatures. In order for this test to be completely reliable in all situations, there could be no overlap 
between signatures of bees from managed colonies and signatures of bees from feral colonies. Ideally, the heaviest signature from any feral bee will still be lighter (i.e., more negative) than the lightest signature from a managed bee. Our second objective was to determine how long a distinct signal will persist between the two types of bees after supplemental feeding is removed. Understanding the temporal trends in signal persistence is the key because supplemental feeding typically occurs periodically rather than year-round. Though little is known about the temporal turnover of carbon in bee tissues, we hypothesized that distinct ${ }^{13} \mathrm{C}$ signals persist in bees from colonies receiving supplemental feed for several months, assuming that ${ }^{13} \mathrm{C}$ from supplemental feed is incorporated into the chitin in the honeybee exoskeleton.

\section{METHODS}

\subsection{Study site}

This study took place from January 2011 to November 2012 in Athens, Georgia, in and around the University of Georgia Bee Lab (located at the UGA Durham Horticulture Farm, Watkinsville, GA). We utilized nine pre-existing honeybee colonies from the UGA bee lab stocks, each composed of a brood box and a shallow honey super. We randomly designated three colonies, each as labeled managed ("LM"), fed managed ("FM"), and unfed managed ("UM").

We also collected 17 feral colonies using swarm traps (Schmidt 1994) in the Oconee block of the Chattahoochee-Oconee National Forest from December 2011 to May 2012. The area surrounding this block of National Forest lacks large honeybee producers to our knowledge, but may have some small-scale beekeepers. After collecting swarms, we moved them to feral bee-specific apiaries at the UGA Bee Lab. Because the swarm-trapping effort was set up for a separate study, we sampled these colonies at various intervals. We designated these as unfed feral ("UF") colonies. Each colony, managed or feral, was given a unique colony ID.
There were two colony types that received supplemental feed (FM and LM) and two colony types that did not (UF and UM). We assumed that unfed feral colonies had not been given supplemental feed as we had captured them from swarms. We did not give unfed managed colonies any supplemental feed after the initiation of the study, and we assumed they only foraged on flowers. This was to simulate the fact that supplemental feeding is often irregular and seasonal, and thus, some managed colonies can go months at a time without supplemental feeding. We gave fed managed and labeled managed colonies supplemental feed once per week for 3 weeks, and we assumed that they foraged on flowers as well as the sugar-water solutions provided. We gave labeled managed colonies a solution that included "labeled" glucose enriched with ${ }^{13} \mathrm{C}$ (detailed below) to allow us to track the turnover of carbon in honeybee workers over time.

We kept the colonies in different apiaries managed by the UGA Bee Lab, separated by type, and apiaries were located at least 2 miles away from each other. We maintained the colonies in separate apiaries to reduce the possibility of robbing and contamination of samples between colony types.

\subsection{Supplemental feeding}

We prepared supplemental feed for FM colonies by creating $3 \mathrm{~L}$ of 50:50 solution (by wt) of deionized water to pure sugarcane sucrose with molarity $2.92144 \mathrm{M}$. We prepared supplemental feed for LM colonies by mixing $1.0 \mathrm{~g} 99 \%$ atomic ${ }^{13} \mathrm{C}$-glucose (Omicron Biochemicals, Inc., South Bend, IN, USA) with pure sugarcane sucrose, creating $3 \mathrm{~L}$ of solution with an identical molarity to the solution used for fed managed colonies and nearly a 50:50 water sugar solution by weight. This solution thus had $0.54 \mathrm{mg}$ of $99 \%$ atomic ${ }^{13} \mathrm{C}$-glucose per gram sucrose. We homogenized mixtures in 3 L Erlenmeyer flasks with a magnetic stirrer bar and a hotplate stirrer and refrigerated until use. We covered the surfaces in aluminum foil, which was changed between preparation of different feeding solutions and thoroughly cleaned the equipment with detergent and then $70 \%$ ethyl alcohol between handling of different sugars to prevent contamination with labeled glucose. 
In mid June of 2012, one 3-L batch of supplemental feed was mixed for the FM colonies and one 3-L batch of supplemental feed was mixed for the LM colonies. One liter of the appropriate solution was put into a typical top feeder, i.e., a sterile glass jar with a metal lid perforated with several small ( $\sim 1 \mathrm{~mm}$ diameter) holes, and placed upside down on the top of each of the six colonies. Feed was replaced twice in 1-week intervals following the initial feeding. Three weeks after the initial feeding, all feedings were removed from the six supplementally fed colonies (FM and LM).

\subsection{Sampling}

We collected honeybee individuals from each of the nine colonies starting at the time of the first supplemental feed (Table I). For the first 3 weeks, we collected individuals from each colony. Individuals from the three LM colonies continued to be collected weekly for 12 more weeks, for a total of 15 weeks, in order to follow comprehensive tracking of the fractionation of the ${ }^{13} \mathrm{C}$ in the honeybee tissues over time. In the other three colony types, UF, UM, and FM, we collected samples biweekly after the first 3 weeks for a total of nine sampling dates over 15 weeks from June to September 2012.

We collected ten individuals from each of the colonies by brushing bees from a frame into a 1-pint
$(0.473 \mathrm{~L})$ lidded glass jar (Ball brand, Daleville, IN, USA) with $\sim 0.125 \mathrm{~L}$ of $70 \%$ ethanol. We collected specimens from each colony into different sample jars to prevent cross-contamination between colonies (Table II). The sampled bees were likely young workers given that they were not foraging. This sampling system allowed for (1) standardization of age between different colony types and (2) the likelihood that a sampled bee had been reared in the presence of the target food type (supplemental sugars, labeled sugars, or absence of labeled food). Once taken back to the lab, we placed bees into small vials filled with $90 \%$ ethanol until they could be pinned and labeled. We pinned bees on separate clean paper towels to prevent cross-contamination.

We dried pinned bees at $50{ }^{\circ} \mathrm{C}$ for $3 \mathrm{~h}$. We used a single hind leg from each specimen for isotope analysis because preliminary analyses showed fractionation among different body parts (Brosi et al. 2009) and because hind legs have a mass range close to the target weight for IRMS given their carbonnitrogen ratio. We chose bees for analysis without wing damage (again, to maintain a consistent age range) and without pollen on their hind leg (which could have affected the isotope values). We removed one hind leg from each specimen with clean forceps, placed it into a tin envelope, and weighed it using a microbalance (accuracy of $0.01 \mathrm{mg}$ ). Weights ranged from 0.50 to $1.05 \mathrm{mg}$. To avoid cross-contamination,

Table I. Quantities of managed bees per colony selected for analysis. Each "sample date" corresponds to a unique date where each sample date is 1 week apart. Sample dates run from 21 June 2012 (sample date 1) to 27 September 2012 (sample date 15).

\begin{tabular}{|c|c|c|c|c|c|c|c|c|c|c|c|c|c|c|c|c|}
\hline \multirow{2}{*}{\multicolumn{2}{|c|}{ Colony type }} & \multicolumn{15}{|c|}{ Sample date } \\
\hline & & 1 & 2 & 3 & 4 & 5 & 6 & 7 & 8 & 9 & 10 & 11 & 12 & 13 & 14 & 15 \\
\hline \multirow[t]{3}{*}{ UM } & 1 & 2 & 2 & 2 & & 2 & & 2 & & 2 & & 2 & & 2 & & 2 \\
\hline & 2 & 2 & 2 & 2 & & 2 & & 2 & & 2 & & 2 & & 2 & & 2 \\
\hline & 3 & 1 & 1 & 1 & & 1 & & 1 & & 1 & & 1 & & 1 & & 2 \\
\hline \multirow[t]{3}{*}{ FM } & 1 & 2 & 2 & 2 & & 2 & & 2 & & 2 & & 2 & & 2 & & 2 \\
\hline & 2 & 2 & 2 & 2 & & 2 & & 2 & & 2 & & 2 & & 2 & & 2 \\
\hline & 3 & 1 & 1 & 1 & & 1 & & 1 & & 1 & & 1 & & 1 & & 1 \\
\hline \multirow[t]{3}{*}{ LM } & 1 & 2 & 2 & 2 & 2 & 2 & 2 & 2 & 2 & 2 & 2 & 2 & 2 & 2 & 2 & 2 \\
\hline & 2 & 1 & 1 & 1 & 1 & 1 & 1 & 1 & 1 & 1 & 1 & 1 & 1 & 1 & 1 & 1 \\
\hline & 3 & 1 & 1 & 1 & 1 & 1 & 1 & 1 & 1 & 1 & 1 & 1 & 1 & 1 & 1 & 1 \\
\hline
\end{tabular}


Table II. Quantities of feral bees per colony selected for analysis.

\begin{tabular}{ccc}
\hline Colony & $\begin{array}{c}\text { Number of } \\
\text { sample dates }\end{array}$ & $\begin{array}{c}\text { Number of individuals } \\
\text { per sample date }\end{array}$ \\
\hline 1.2 & 1 & 3 \\
1.3 & 1 & 3 \\
1.4 & 1 & 3 \\
1.7 & 1 & 3 \\
1.8 & 3 & $5 / 4^{\mathrm{a}}$ \\
2.1 & 2 & 3 \\
2.2 & 1 & 3 \\
2.3 & 1 & 3 \\
2.4 & 2 & 5 \\
2.5 & 2 & 5 \\
2.11 & 1 & 3 \\
3.1 & 1 & 3 \\
3.3 & 1 & 3 \\
3.5 & 3 & 5 \\
3.6 & 1 & 3 \\
3.9 & 1 & 3 \\
3.11 & 1 & 3 \\
\hline
\end{tabular}

\footnotetext{
${ }^{\text {a }}$ One of the three sample dates had only four samples due to sample mass restrictions (i.e., sampled hind legs were outside of the instrument bounds for mass); the other two had five samples
}

we covered work surfaces with aluminum foil and thoroughly cleaned tools and workspace with ethyl alcohol between samples. After weighing, tin sample envelopes were crimped and placed in a labeled microwell plate.

We sent samples to the Boston University Stable Isotope Facility (Department of Biology, Boston, MA) for analysis, where they were processed using an elemental analyzer interfaced to a GV Instruments Isoprime isotope ratio mass spectrometer ( $\mathrm{GV}$ Instruments Ltd., Manchester, UK). The BU Isotope Facility made mass corrections to ensure that sample mass did not affect isotopic measurements.

\subsection{Data analysis}

Stable carbon isotopes include ${ }^{13} \mathrm{C}$ and ${ }^{12} \mathrm{C}$. The relative ratio of ${ }^{13} \mathrm{C}$ to ${ }^{12} \mathrm{C}$ can be detected using IRMS. Carbon isotope ratios are expressed in $\delta^{13} \mathrm{C}$ units, signifying parts per thousand (\%) of the heavy isotope relative to an international standard value. In the case of carbon, the standard is Pee Dee Belemnite (PDB), a cretaceous fossil from North Carolina that is thus defined to have a $\delta^{13} \mathrm{C}$ value of zero (Craig 1957). As the PDB standard contains a relatively high concentration of ${ }^{13} \mathrm{C}$, most compounds found in nature have a negative $\delta^{13} \mathrm{C}$ signature in comparison. The formula for $\delta^{13} \mathrm{C}$ is:

$$
\delta^{13} \mathrm{C}=\left(\left(R_{\text {sample }} / R_{\text {standard }}\right)-1\right) \times 1,000
$$

where $R_{\text {sample }}$ is the ratio of ${ }^{13} \mathrm{C} /{ }^{12} \mathrm{C}$ of the sample and $R_{\text {standard }}$ is the ratio of ${ }^{13} \mathrm{C} /{ }^{12} \mathrm{C}$ of PDB.

To test for statistical differences in $\delta^{13} \mathrm{C}$ values between different management (feral vs. managed) and feeding groups, we used linear mixed effects models (LMMs) with colony ID as a random effect, with the "Ime4" package (Bates et al. 2011) in the R Statistical Programming Language (R Development Core Team 2012). We took this approach because different bee individuals from the same colony cannot be considered independent samples, and mixed effects models allow for the use of all data points while taking into account the non-independence of colony groups (e.g., Bolker et al. 2009). We used Gaussian errors because the response variable $\left(\delta^{13} \mathrm{C}\right)$ is continuous, and errors were approximately normally distributed. To test for the significance of colony type (UF vs. UM; UF vs. FM; UF vs. UM+ UF), for each test, we conducted likelihood ratio tests comparing a model including colony type (as the only fixed effect) plus colony ID (random effect) to a null model that included no fixed effects (random effect only) (e.g., Bolker et al. 2009). We also calculated pairwise, post hoc comparisons between each colony type using the "glht" function from the "multcomp" package for R (Hothorn et al. 2008).

Because our goal was to assess the efficacy of stable isotope markers for assignment of colony type, we used linear discriminant function analysis to classify bee specimens into colony types using the "lda" function from the "MASS" library for R (Venables and Ripley 2002). We characterized the proportion of correct classifications and used $\chi^{2}$ tests to test the statistical significance of the classification results. 


\section{RESULTS}

We analyzed the carbon isotopic signature of 257 honeybee individuals. Of these, 91 individuals were from UF colonies ( $N=17$ colonies), 45 were from FM colonies ( $N=3$ colonies), 46 were from UM colonies ( $N=3$ colonies), and 75 were from LM colonies ( $N=3$ colonies). Distributions of isotopic signatures within each colony type are shown in Figure 1 . The $\delta^{13} \mathrm{C}$ values of the samples ranged from -26.76 to $-13.80 \%$. Values on both ends of the spectrum reside within the standard ranges for $\mathrm{C} 3$ and $\mathrm{C} 4$ plants, but not within the average range of isotopic signatures for pure cane sugar $(-11.65$ to $-10.75 \%$ ).

There was overlap in the spread of isotopic signatures between feral and managed bees, including overlap between fed managed bees and unfed feral bees (Figure 1). Although there was overlap in the carbon isotopic signatures of the different colony types, there was a significant difference between the isotopic signatures of the feral and fed managed (UF vs. FM) bees (linear mixed effects model, LMM; $\chi^{2}=4.88$, $P=0.027$ ). That difference did not hold when comparing feral and both categories of managed bees considered together (UF vs. FM+UM; LMM, $\left.\chi^{2}=1.86, P=0.172\right)$. Similarly, there was no significant difference between feral and unfed managed bees (UF vs. UM), and moreover, the means of those two groups were essentially identical (LMM, $\chi^{2} \approx 0, P=0.99$ ). Post hoc pairwise comparisons between groups are shown as letters in Figure 1.

After the feeding began, isotopic signatures became heavier over time in both the FM and LM bees, and values continued to increase for

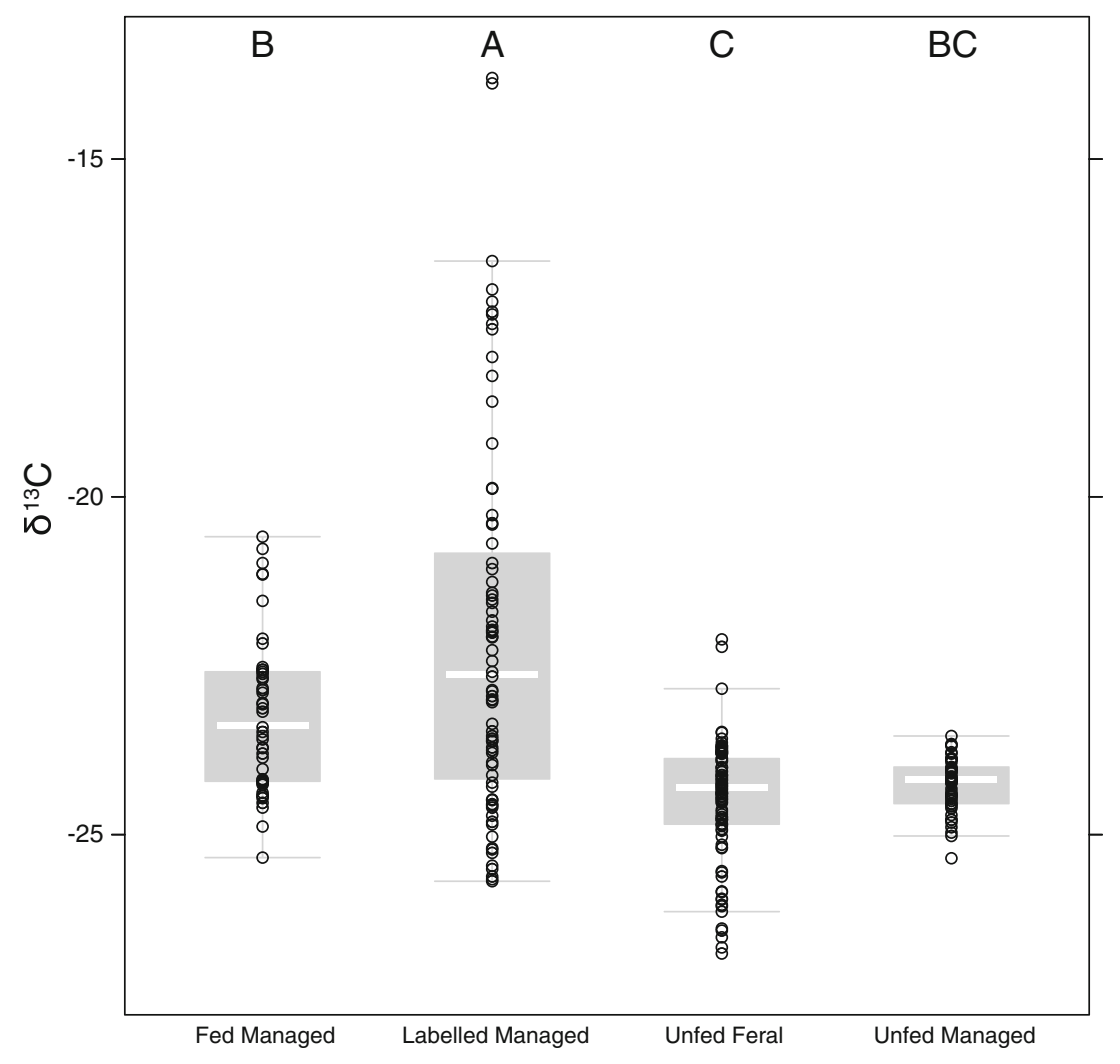

Figure 1. Carbon isotopic signature values by colony type. Different letters depict statistical differences between groups, as determined by post hoc comparisons from a linear mixed effects model. 
about 5 weeks after feeding was removed (Figure 2; up to approximately sample date 8). As expected, the isotopic signatures of the fed labeled individuals were significantly heavier on average than those of the fed managed bees (pooled across all time points, LMM, $\chi^{2}=6.15$, $P=0.013$ ). After sample date $8, \delta^{13} \mathrm{C}$ values in both types of fed colonies began to decline and were ultimately indistinguishable from the unfed colonies by the end of the 15-week study.

When comparing feral to managed bees (excluding those fed with labeled glucose), discriminant function analyses correctly classified $58 \%$ of bee specimens. While this resolution is likely not strong enough for most practical applications, it is statistically significantly relative to random assignment $\left(\chi^{2}=\right.$ 13.10, $\mathrm{df}=2, P=0.00143)$. The proportion of correct classifications was higher in feral $(62 \%)$ than in managed bees $(54 \%)$. When comparing fed managed bees to feral bees, the probability of correct classification improved to $73 \%$ overall (assuming equal numbers of feral and managed bees), a highly significant result $\left(\chi^{2}=38.73, \mathrm{df}=1, P=4.86 \mathrm{e}^{-10}\right)$, with correct classification of nearly all (97\%) feral individuals and $49 \%$ of managed bees. Comparing unfed managed bees to feral bees, classification was poor, with correct classification of only $48 \%$ of individuals (NS; $\chi^{2}=0.067, \mathrm{df}=1, P=0.796$ ). Classification was highly polar, correctly classifying nearly all feral bees (98\%) but no unfed managed bees $(0 \%)$.

\section{DISCUSSION}

\subsection{Overview}

The aims of this study were to (1) determine if stable isotopes of carbon could reliably

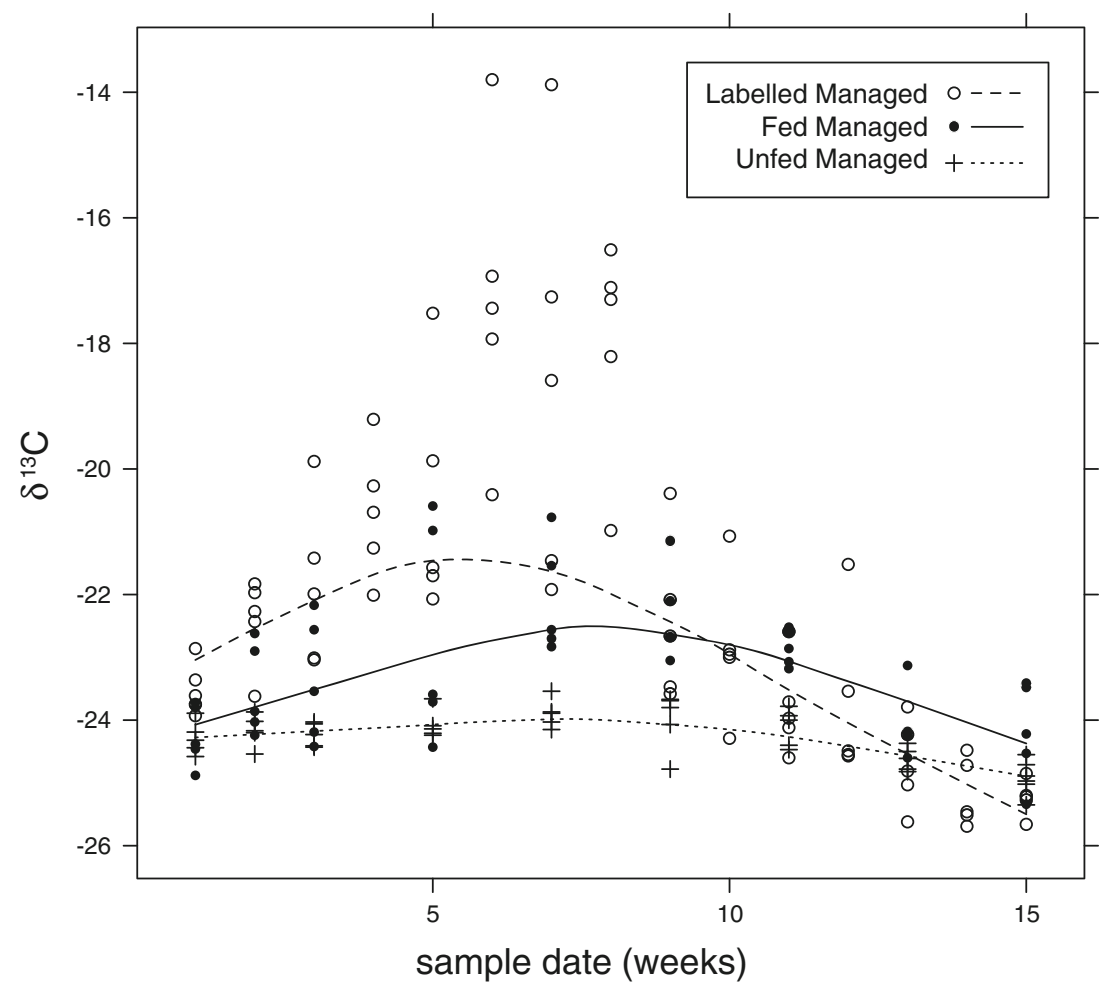

Figure 2. Isotopic signatures of FM, UM, and LM colonies by date over the 15 -week sample period. Trend lines were generated using the "smooth" command in the lattice graphics package for R. 
distinguish feral from managed honeybees and (2) estimate the turnover time of carbon from supplemental feed in honeybee workers. These aims are interrelated in that reliable differentiation of feral from managed bees depends on the length of time the signature of enriched ${ }^{13} \mathrm{C}$ lasts after feeding of $\mathrm{C} 4$-enriched supplemental feed ends.

We found a significant difference between the isotopic signatures of fed managed and unfed feral bees, indicating some potential for differentiating managed honeybees receiving supplemental feed from feral honeybees using stable carbon isotopic ratios. While we did find statistically significant differences between fed managed and unfed feral bees, there was still overlap in the ranges of carbon isotope values in the two groups. The temporal signal of feeding was very short-term, however, indicating that managed and feral bees cannot be positively differentiated at any time of year. Classifications based on $\delta^{13} \mathrm{C}$ using discriminant function analysis supported these findings, with about $75 \%$ correct classification when comparing fed managed and feral bees, which dropped to below $50 \%$ when comparing unfed managed and feral individuals. Our data suggest that during summer in Georgia, managed bees receiving supplemental feed can be differentiated from feral bees up to 6 weeks after feeding is removed. Due to the time frame in which the study was completed and the setup of the experiment, we did not have a sufficient number of samples to test for statistical significance in the length of time for which there remained a significantly different isotopic signature between the fed and unfed bees.

\subsection{Mechanisms for rapid turnover of heavy signatures}

The relatively short timescale of the heavier isotopic signals in supplementally fed honeybee tissue can most likely be accounted for by honeybee biology and/or potential limitations of the study design. In terms of bee biology, three aspects are relevant: (1) general patterns of honeybee worker development, (2) the patterns of carbon isotope fractionation that occur during development, and (3) seasonal changes in nectar/supplemental sugar consumption and storage within a colony.

First, the length of development and lifespan of honeybee workers most likely affected the length of time for which a heavier signature persisted in our data. Worker bees have a 21-day developmental period after the egg is laid before they emerge as adults, and in summer, an average adult lifespan is $\sim 28$ days. As worker bees age, their roles in colony maintenance change ("age-based polytheism"; e.g., Graham 1992). The younger bees work inside the hive, cleaning, handling food, and building and maintaining comb and brood cells, and begin foraging when they are 18 days old (Sakagami 1953; Winston and Fergusson 1985). It is likely that most of the bees collected for this analysis were relatively young, likely pre-foragers. We sampled bees from a frame inside the hive, and we specifically avoided choosing individuals for analysis that had wing damage, a sign of aging. If supplemental feed was transferred into brood cells relatively soon after it was provided to the hive, the 3 weeks of development plus an additional 2 to 3 weeks working inside the hive amounted to an equivalent length of time for which the distinct isotopic signature persisted. This scenario also accounts for the time lag in the spike of carbon isotopic signatures in the bees fed labeled glucose.

Second, there is little information available on the fractionation of the carbon isotopes in the developing individual honeybee. Sources of carbon in growing tissue could originate from pollen, nectar, sugar solution, or most likely, a combination of the three, provisioned to honeybee brood in individual cells via worker bees. Brood cells are capped with wax shortly before the molt to prepupae, and thus, no new nutritive provisions are added after capping. It is likely that chitin in the honeybee exoskeleton - which may have been the dominant form of carbon in our hind leg samples-has different carbon fractionation processes than other tissues or hemolymph. Diet-tissue fractionation in black fly (Anopheles arabiensis, Culicidae) larvae varies from 1 to $2 \%$ (Overmyer et al. 2008), 
but the underlying mechanisms remain unknown. Using this as a baseline, future studies should examine the extent of honeybee diettissue fractionation in various tissues.

Third, the fastest carbon isotopic turnover in a honeybee colony likely occurs in the summer. This may be due to shorter worker lifespan (two to three times shorter relative to winter; Graham 1992) coupled with an increase in the production of offspring (and thus high resource use). Short lifespans and high resource demands mean that colony carbon turnover may have hit an annual peak during the time of this study. Similarly, because this study took place in the summer, it is likely that little supplemental feed was stored and was instead either transferred directly to brood cells or consumed immediately by the workers. Thus, isotopic turnover between colonies receiving supplemental feed and unfed colonies may be shorter in the summer relative to other times of year.

In addition to biological mechanisms that could be responsible for the short duration of supplemental feeding signals, it is possible that methodological shortcomings have contributed to this result. We stored the bees in $90 \%$ ethyl alcohol from collection until pinned and dried, and there is a possibility that storage in alcohol weakened the carbon isotopic signatures of our honeybee samples. We stored the feral bees in the alcohol for a longer period of time, so if there were an effect, it could have been amplified in the feral bees. In addition, the feral colonies in this study were established from swarm traps. While swarm traps were placed in isolated areas of the Oconee block of the Chattahoochee-Oconee National Forest, some of the feral swarms could have originated from managed colonies. Thus, the isotopic differences between feral and managed bees may have been obscured by the inclusion of colonies with a signal of supplemental feeding in our "unfed feral" category.

\subsection{Applications of isotope analysis in honeybees}

Although the use of stable carbon isotopes may not be applicable in differentiating feral and managed honeybees in all situations, this technique holds promise for applications in broader ecological studies. If it is known that managed colonies are receiving supplemental feed, relative distributions of habitat and foraging location preferences could be potentially identified with the use of carbon isotopic signatures of bees foraging in a specific area (e.g., Brosi et al. 2009).

In addition, the carbon isotopic signatures of nectar in flowers and plants vary geographically, with climate and rainfall having a major effect on which isotopes of carbon they absorb from the atmosphere. With increased drought stress, plants close their stomates (leaf pores) in order to conserve moisture. This leads to less discrimination against ${ }^{13} \mathrm{C}$ and a subsequent heavier isotopic signature in a drought-stressed plant relative to a plant receiving adequate moisture (Peterson and Fry 1987). Because of this, there may be potential in situations of drought or extreme moisture for the use of isotopic signatures to differentiate feral and managed bees.

An example of conditions where this concept might apply is areas with high rainfall such as tropical rainforests, where it is assumed that the feral honeybee populations are foraging on $\mathrm{C} 3$ plants that experience minimal drought stress, producing relatively light carbon isotopic signatures due to the presence of ample moisture (Farquhar et al. 1989; Brosi et al. 2009). In such a context, if it is known that beekeepers are feeding their managed bees with C4-based supplemental feed, it may be possible to determine more definitively whether a honeybee specimen is from a managed or feral colony. Supplemental feeding does occur in some such tropical areas because even in the absence of drought stress, there can still be nectar dearths at different times of year.

Although there was overlap in the isotopic signature values of managed and feral bees in our study, there may be potential for distinguishing feral and managed honeybees if the isotopic signature of a particular specimen falls outside a specific range. For example, in this study, the heaviest isotopic value of a feral bee is -23.48 and the lightest signature of a fed 
managed bee is -25.6 . Although the ranges of isotopic signals overlap, with further research, it may be possible to establish a range of values on either side of this overlap zone (likely region-specific) that could be used to discriminate feral from managed bees. Our labeling experiment, however, presents a potential counter-argument to this idea: the isotopic signals of the fed managed and fed labeled bees became indistinguishable from unfed managed bees in the same amount of time in our experiment, so a larger gap in isotopic signatures may not impact the timeframe over which there is a distinct signature.

\subsection{Future directions}

Future research is necessary in several areas, including (1) seasonal isotopic turnover, (2) the relationship between duration of feeding and duration of signal persistence, and (3) stable carbon isotope fractionation in honeybee tissue development. First, the variation in carbon turnover in bee colonies between seasons should be explored in the future to help determine the applicability of using stable isotopes to differentiate feral and managed bees. Second, exploring the relationship between duration of feeding and the duration of heavy isotopic signal persistence could provide further insight on the effect of continued feeding on the turnover rate of carbon in honeybee tissue. This is particularly salient given that most beekeepers in the USA provide supplemental feed for periods longer than 3 weeks (the timescale of our feeding experiment) and, thus, exploring if longer feeding periods are correlated with a longer persistence of distinguishable isotopic signatures could be useful for differentiating feral and managed honeybees for longer periods of time. Finally, given that so little is known about the fractionation of carbon in developing honeybee tissues, further research could be done, for example, via labeling pollen with ${ }^{13} \mathrm{C}$ to determine the extent to which pollenderived carbon is involved in exoskeleton formation and to develop an understanding of carbon turnover from pollen in different bee tissues.

\subsection{Conclusion}

In conclusion, we were able to detect a ${ }^{13} \mathrm{C}$ signal from supplemental sugar feeding in bee tissues consistent with isotope studies in a range of systems including bees (Brosi et al. 2009). Although stable carbon isotopic ratios cannot be used to differentiate feral from managed bees in all situations, this study gives insight into the temporal turnover of ${ }^{13} \mathrm{C}$ in honeybee colonies. There is great potential for using isotopes in diet and foraging studies, especially with more work on understanding carbon turnover in honeybees and other insects.

\section{ACKNOWLEDGMENTS}

We thank B. Nolan, P. Quinn, and N. Weaver for their contributions to the apiary management and B. Tran, E. Lake, and D. Gruenewald for their assistance in pinning bees in the lab. H. Briggs, E. Dobbs, D. Tarpy, and two anonymous reviewers provided constructive comments on the manuscript. B. Ryan and D. Barr both provided helpful discussion on analytic chemistry and the use of a microbalance. We are grateful to the ChattahoocheeOconee National Forest for permission to collect feral swarms. This work was funded by the US Department of Agriculture (NIFA 2011-67013-30131 to BJB, KSD, and J. De Roode), the US National Institutes of Health (R01109501-01, part of the joint NIH-NSF-USDA Ecology and Evolution of Infectious Diseases program, to J. De Roode, BJB, and KSD), Emory University (Scholarly Inquiry and Research at Emory grants and the James G. Lester Environmental Studies Research Grant, both to LMA), and the North American Pollinator Protection Campaign (Honey Bee Health Grant to BJB, KSD, and LLM).

Distinction entre abeilles sauvages et abeilles de ruches (Apis mellifera) par l'utilisation d'isotopes stables du carbone

colonie naturelle / fractionnement isotopique / photosynthèse / carbone

Unterscheidung von wildlebenden und imkerlich gehaltenen Honigbienen (Apis mellifera) anhand von stabilen Kohlenstoff-Isotopen

Wildlebende Honigbienen / stabile Isotope / Kohlenstoff / Photosyntheseverlauf / isotopische Fraktionierung 


\section{REFERENCES}

Bates, D. Maechler, M., Bolker, B. (2011). lme4: Linear mixed-effects models using S4 classes. R package version 0.999375-42. http://CRAN.R-project.org/ package $=1 m e 4$. Accessed March 2013

Bolker, B.M., Brooks, M.E., Clark, C.J., Geange, S.W., Poulsen, J.R., Stevens, M.H.H., White, J.S. (2009) Generalized linear mixed models: a practical guide for ecology and evolution. Trends Ecol. Evol. 24, 127-135

Brosi, A.R., Harkins, W.D. (1937) The abundance ratio of the isotopes in natural or isotopically separated carbon. Phys. Rev. 52, 472-474

Brosi, B.J., Daily, G.C., Chamberlain, C.P., Mills, M. (2009) Detecting changes in habitat-scale bee foraging in a tropical fragmented landscape using stable isotopes. Forest Ecol. Manag. 258, 1846-1855

Craig, H. (1957) Isotopic standards for mass spectrometric analysis of carbon dioxide. Geochim. Cosmochim. Acta. 12, 113-140

Daniele, G., Wytrychowski, M., Batteau, M., Guibert, S., Casabianca, H. (2011) Stable isotope ratio measurements of royal jelly samples for controlling production procedures: impact of sugar feeding. Rapid Commun. Mass Spectrom. 25, 1929-1932

Doner, L.W., White, J.W. (1977) Carbon-13/Carbon-12 ratio is relatively uniform among honeys. Science 197, 891-892

Elflein, L., Raezke, K. (2008) Improved detection of honey adulteration by measuring differences between $13 \mathrm{C} / 12 \mathrm{C}$ stable carbon isotope ratios of protein and sugar compounds with a combination of elemental analyzer-isotope ratio mass spectrometry and liquid chromatography-isotope ratio mass spectrometry ( 813 C-EA/LC-IRMS). Apidologie 39, 574-587

Farquhar, G.D., Ehleringer, J.R., Hubick, K.T. (1989) Carbon isotope discrimination and photosynthesis. Annu. Rev. Plant Phys. 40, 503-537

Graham, J.M. (1992) The Hive and the Honey Bee. Dadant \& Sons, Hamilton

Hobson, K.A. (1999) Tracing origins and migration of wildflower using stable isotopes: a review. Oecologia 120, 314-326

Hothorn, T., Bretz, F., Westfall, P. (2008) Simultaneous Inference in General Parametric Models. Biom. J. 50(3), 346-363

Kelly, J.F. (2000) Stable isotopes of carbon and nitrogen in the study of avian and mammalian trophic ecology. Can. J. Zool. 78, 1-27

Kennedy, B.P., Folt, C.L., Blum, J.D., Chamberlain, C.P. (1997) Natural isotopic markers in salmon. Nature 387, 766-767

Koziet, J., Rossmann, A., Martin, G.J., Ashurst, P.R. (1993) Determination of carbon-13 content of sugars of fruit and vegetable juices: A European inter-laboratory comparison. Anal. Chim. Acta 271, 31-38
Martin, S.J., Highfield, A.C., Bretell, L., Villalobos, E.M., Buge, G.E., Powell, M., Nikaido, S., Schroeder, D.C. (2012) Global honey bee viral landscape altered by a parasitic mite. Science 336, 1304-1306

O'Brien, D.M., Schrag, D.P., del-Rio, C.M. (2000) Allocation to reproduction in a hawkmoth: a quantitative analysis using stable carbon isotopes. Ecology 81, 2822-2831

Oldroyd, B.P. (2007) What's killing American honey Bees? PLoS Biol 5, 1195-1199

Ostrom, P.H., Colunga-Garcia, M., Gage, S.H. (1997) Establishing pathways of energy flow for insect predators using stable isotope ratios: field and laboratory evidence. Oecologia 109, 108-113

Overmyer, J.P., MacNeil, M.A., Fisk, A.T. (2008) Fractionation and metabolic turnover of carbon and nitrogen stable isotopes in black fly larvae. Rapid Commun. Mass Spectrom. 22, 694-700

Oxley, P., Spivak, M., Oldroyd, B. (2010) Six quantitative trait loci influence task thresholds for hygienic behavior in honeybees (Apis mellifera). Mol. Ecol. 19, 1452-1461

Peterson, B.J., Fry, B. (1987) Stable isotopes in ecosystem studies. Annu. Rev. Ecol. Syst. 18, 293-320

Phillips, D.L. (2001) Mixing models in analyses of diet using multiple stable isotopes: a critique. Oecologia 127, 166-170

Potts, S.G., Beismeijer, J.C., Kremen, C., Neumann, P., Schweiger, O., Kunin, W.E. (2010) Global pollinator declines: trends, impacts, and drivers. Trends Ecol. Evol. 25, 345-353

R Development Core Team (2012) R: A language and environment for statistical computing. $\mathrm{R}$ Foundation for Statistical Computing, Vienna, Austria. ISBN 3-900051-07-0, http://www.Rproject.org/. Accessed March 2013

Rosenkranz, P., Aumeier, P., Ziegelmann, B. (2010) Biology and control of Varroa destructor. J. Invertebr. Pathol. 103, S96-S119

Sakagami, S.F. (1953) Untersuchungen ber die Arbeitsteilung in einem Zwergvolk der Honigbiene. Beitr ge zue Biologie des Bienenvolkes, Apis mellifera L. I. Jap. J. Zool. 11, 117-185

Schmidt, J. (1994) Attraction of reproductive honey-bee swarms to artificial nests by Nasonov pheromone. J. Chem. Ecol. 20, 1053-1056

Seeley, T.D. (2007) Honey bees of the Arnot Forest: a population of feral colonies persisting with Varroa destructor in the northeastern United States. Apidologie 38, 19-29

Spivak, M., Mader, E., Vaughan, M., Euliss Jr., N.H. (2011) The plight of the bees. Environ. Sci. \& Technol. 45, 1-34

Venables, W.N., Ripley, B.D. (2002) Modern Applied Statistics with S, 4th edn. Springer, New York

Winston, M.L., Fergusson, L.A. (1985) The effect of worker loss on temporal caste structure in colonies of the honey bee (Apis mellifera L.). Can. J. Zool. 63, 777-780 